\title{
PEMAKAIAN JARGON SATUAN POLISI PAMONG PRAJA PADA MARKAS KOMANDO KABUPATEN KARAWANG (KAJIAN SOSIOLINGUISTIK)
}

\author{
Riyadhul Haq ${ }^{1}$, Tri Pujiati ${ }^{2}$, dan Dien Mardiana $\mathbf{Y}^{3}$ \\ Universitas Pamulang \\ ${ }^{1}$ riozule@yahoo.co.id \\ 2dosen00356@unpam.ac.id \\ dosen00155@unpam.ac.id
}

\begin{abstract}
Abstrak
Penelitian ini bertujuan untuk (1) Mendeskripiskan bentuk kode komunikasi Satuan Polisi Pamong Praja pada Markas Komando Kabupaten Karawang.(2) Mendeskripsikan bentuk lingual pada jargon yang digunakan oleh Satuan Polisi Pamong Praja pada Markas Komando Kabupaten Karawang. (3) Mendeskripsikan makna jargon ditinjau dari komponen tutur Satuan Polisi Pamong Praja Pada Markas Komando kabupaten Karawang. Berdasarkan analisis data, diperoleh simpulan: (1) Bentuk kode komunikasi yang digunakan oleh Satuan Polisi Pamong Praja Pada Markas Komando Kabupaten Karawang yaitu sandi struktural, sandi alphabet/lokal Indonesia, sandi angka, dan sandi kata. (2) Bentuk lingual pada jargon Satuan Polisi Pamong Praja Pada Markas Komando Kabupaten Karawang terdiri dari bentuk Kata, Frasa Numeralia dan Frasa Nomina.(3) makna jargon di tinjau dari komponen tutur penulis mengacu pada teori SPEAKING yaitu Setting and Scene, Participants, End :Purpose and Goal, Act Squences, Key : Tone or Spirit of Act, Instrumentalities, Norms Of Interaction And Interpretation, dan Genres.
\end{abstract}

\section{Kata Kunci : Sosiolinguistik, Jargon, Satuan Polisi Pamong Praja.}

\section{Pendahuluan}

Berkembangnya era mordenisasi dapat membangunkan pikiran manusia yang lebih baik sehingga diperlukan adanya alat-alat yang lebih canggih dalam kegiatan berkomunikasi. Semakin berkembangnya era modernisasi ini kualitas teknologi dan informasi di Indonesia pun ikut serta meningkat ke arah yang lebih canggih lagi sehingga segala informasi dan teknologi terhadap masyarakat pun dapat meningkat ke era modernisasi lagi. Berkembangnya teknologi di Indonesia di era modernisasi ini 
dapat memberikan kemudahan bagi masyarakat dalam berkomunikasi melalui bantuan alat komunikasi seperti pesawat telepon, telepon genggam, e-mail, faksimil, televisi, radio, HT, dan sebagainya.

Sejalan dengan uraian permasalahan di atas, penulis akan menghubungkan pembahasan tersebut dengan menggunakan kajian sosiolinguistik. Sosiolinguistik merupakan gabungan dari kata sosiologi dan linguistik. Sosiologi adalah kajian yang objektif dan ilmiah mengenai manusia dalam masyarakat dan mengenai lembagalembaga serta proses sosial yang ada di dalam masyarakat. Aslinda dan Syafyahya (dalam Chaer dan Agustina, 1995:3). Suatu kelompok dan lembaga yang berada di tengah-tengah masyarakat pasti mempunyai ciri khas tertentu. Hal itu menunjukan bahwa ciri khas yang dimilikinya adalah lambang serta identitas kelompok atau lembaganya. Dari ciri khas tersebut hanya dipahami dan dimengerti oleh mereka dalam melaksanakan kegiatan pada internalnya. Salah satunya adalah bahasa yang dipakai oleh Satuan Polisi Pamong Praja (SATPOL PP). Bahasa yang dipakai oleh Satuan Polisi Pamong Praja adalah Jargon. Satuan Polisi Pamong Praja adalah organisasi perangkat daerah yang berfungsi untuk mengawal dalam penegakan peraturan daerah. (Perda) berdasarkan peraturan yang ditetapkan oleh daerah itu sendiri. Satuan Polisi Pamong Praja ketika di dalam bertugas pada setiap kegiatan atau aktifitas di lingkungan pemerintah daerah tidak terlepas dari koordinasi dan laporan terhadap pimpinan, rekan, dan jajaran lainnya.

Dalam kegiatan yang dilakukan oleh Satuan Polisi Pamong Praja menggunakan media/alat berupa HT (Handy Talky) yang di dalamnya terdapat bahasa rahasia atau khusus yang digunakan di lingkungan kerja Satuan Polisi Pamong Praja ialah Jargon. Jargon adalah suatu bahasa berbentuk kode yang telah dibuat oleh kelompok/lembaga sehingga tidak semua orang lain tidak memahami dan mengetahuinya.

Berikut ini adalah salah satu contoh tuturan yang menjadi jargon dan digunakan oleh Satuan Polisi Pamong Praja Pada Markas Komando Kabupaten Karawang:

\section{Data 001}

Wibawa : Kawasan Dewi Sri, Delta Alpa dan Anggota 
segera ditertibkan.

Delta : Anggota, Merapat, ke Dewi Sri.

Anggota $\quad: 86$, Komandan!

Pada data 001 di atas terdapat contoh penggunaan jargon yang digunakan oleh Satpol PP. Kegiatan tersebut merupakan penggunaan bahasa jargon yang digunakan oleh Satuan Polisi Pamong Praja pada Markas Komando Kabupaten Karawang. Penutur (Kasatpol PP/Wibawa) memberikan perintah kepada Danru I dengan anggota untuk segera menertibkan kawasan Dewi Sri yang merupakan kawasan prostitusi. Setelah itu Komandan Regu (Danru/Delta) menghimbau kepada semua anggota untuk merapat ke Dewi Sri. Penutur Anggota menjawab dapat dimengerti, komandan!. Pada data 001 di atas, Jargon Wibawa, Delta Alpa dan 86 merupakan salah satu kode yang biasa digunakan oleh Satuan Polisi Pamong Praja dalam melaksanakan kegiatan.

\section{Metode Penelitian}

Pada penelitian ini penulis akan menggunakan metode deskriptif kualitatif untuk mendeskripsikan bentuk lingual serta makna jargon berdasarkan komponen tutur pada Satpol PP di Karawang. Sumber data yang digunakan dalam penelitian ini dikelompokan menjadi dua yaitu data primer dan data sekunderr. Sumber data primer yang didapatkan penulis bersumber dari peristiwa tutur anggota Satuan Polisi Pamong Praja Pada Markas Komando Kabupaten Karawang. Sumber data sekunder dalam penelitian ini penulis dapatkan dari berbagai media, baik buku, internet, skripsi dan referensi lainnya. 


\section{Pembahasan}

\section{Bentuk Lingual Pada Jargon Satuan Polisi Pamong Praja Pada Markas Komando Kabupaten Karawang \\ a. Bentuk Lingual 'Kata' Pada Jargon Satuan Polisi Pamong Praja Pada Markas Komando Kabupaten Karawang}

Kata adalah suatu unit dari suatu bahasa yang mengandung arti dan terdiri dari satu atau lebih morfem.. Berikut bentuk lingual yang termasuk ke dalam kata benda :

Ambon, Bandung, Cepu, Demak, Endeh, Flores, Garut, Halong, Irian, Jepara, Kendal, Lombok, Medan, Namlea, Opak, Pati, Queen, Rembang, Solo, Timur, Umar/Ungaran, Viktor, Willis, X-Treem, Yongki, Zero, Wibawa (Kepala Satuan), Tameng (Kapelops), Taruna (Berita / Informasi). Gelombang (Jam/Waktu), Semut (Pelajar), Lalat (Mahasiswa), Pangkalan (Rumah/Kediaman),Cangkulan (Kantor/Tempat Kerja), Gajah (Derek), Cicak (Pemulung), Komando (Kantor Polisi), Tikar (Surat), Laka(Kecelakaan), Sepi(Senjata Api), Sajam (Senjata Sajam), Curat(Pencurian dengan pemberatan), Curas (Pencurian dengan kekerasan), Curanmor (Pencurian kendaraan bermotor), Monik(Anak), Wayang (Intel/Serse), Panah (Polantas).

(1) "Ambon" merupakan kata jargon yang tergolong kelas kata benda. Pada pengggunaan jargon, kata benda "Ambon" digunakan sebagai sandi yang dapat memperjelas untuk ditujukan oleh suatu tempat, benda, ataupun sebuah tim karena diawali oleh huruf "A" kapital.

(2) "Bandung" merupakan bentuk jargon yang tergolong kelas kata benda. Dalam penggunaan jargon, kata benda "Bandung" digunakan sebagai sandi yang dapat memperjelas untuk ditujukan oleh suatu tempat, benda, ataupun sebuah tim karena diawali oleh huruf "C" kapital.

(3) "Cepu" merupakan bentuk jargon yang tergolong kelas kata benda. Dalam penggunaan jargon, kata benda "Cepu" digunakan sebagai sandi yang dapat memperjelas untuk ditujukan oleh suatu tempat, benda, ataupun sebuah tim karena diawali oleh huruf "C" kapital.

(4) "Demak" merupakan bentuk jargon yang tergolong kelas kata benda. Penggunaan jargon, kata benda "Demak" digunakan sebagai sandi yang dapat 
memperjelas untuk ditujukan oleh suatu tempat, benda, ataupun sebuah tim, dengan nama “Tim Demak" karena diawali oleh huruf "D” kapital.

(5) "Endeh" merupakan bentuk jargon yang tergolong kelas kata benda. Dalam penggunaan jargon, kata benda "Endeh" digunakan sebagai sandi yang dapat memperjelas untuk ditujukan oleh suatu tempat, benda, ataupun sebuah tim karena diawali oleh huruf "E” kapital.

(6) "Flores" merupakan bentuk jargon yang tergolong kelas kata benda. Dalam penggunaan jargon, kata "Flores" digunakan sebagai sandi yang dapat memperjelas untuk ditujukan oleh suatu tempat, benda, ataupun sebuah tim, dengan nama "Tim Flores" karena diawali oleh huruf "F” kapital.

(7) "Garut" merupakan yang tergolong kelas kata benda. Penggunaan jargon, kata "Garut" digunakan sebagai sandi yang dapat memperjelas untuk ditujukan oleh suatu tempat, benda, ataupun sebuah tim, dengan nama "Tim Garut" karena diawali oleh huruf "G” kapital.

(8) "Halong" merupakan yang tergolong kelas kata benda. Dalam penggunaan jargon, kata "Halong” digunakan sebagai sandi yang dapat memperjelas untuk ditujukan oleh suatu tempat, benda, ataupun sebuah tim, dengan nama "Tim Garut" karena diawali oleh huruf "H” kapital.

(9) "Irian" merupakan bentuk jargon yang tergolong kelas kata benda. Penggunaan jargon, kata "Irian" digunakan sebagai sandi yang dapat memperjelas untuk ditujukan oleh suatu tempat, benda, ataupun sebuah tim karena diawali oleh huruf "I" kapital.

(10) "Jepara" merupakan yang tergolong kelas kata benda. "Jepara" digunakan sebagai sandi yang dapat memperjelas untuk ditujukan oleh suatu tempat, benda, ataupun sebuah tim karena awali oleh huruf "J" kapital.

"Kendal" merupakan bentuk jargon yang tergolong kelas kata benda. "Kendal" digunakan sebagai sandi yang dapat memperjelas untuk ditujukan oleh suatu tempat, benda, ataupun sebuah tim, dengan nama "Tim Kendal" karena nama depannya diawali oleh huruf " $\mathrm{K}$ " kapital. 
(12) "Lombok" merupakan bentuk jargon yang tergolong kelas kata benda. "Lombok" digunakan sebagai sandi yang dapat memperjelas untuk ditujukan oleh suatu tempat, benda, ataupun sebuah tim, dengan nama "Tim Lombok" Karena nama depannya diawali oleh huruf "L" kapital. "Medan" merupakan bentuk jargon yang tergolong kelas kata benda. "Medan" digunakan sebagai sandi yang dapat memperjelas untuk ditujukan oleh suatu tempat, benda, ataupun sebuah tim, dengan nama "Tim Medan" karena nama depannya diawali oleh huruf "M" kapital.

(14) "Namlea" merupakan bentuk jargon yang tergolong kelas kata benda. "Namlea" digunakan sebagai sandi yang dapat memperjelas untuk ditujukan oleh suatu tempat, benda, ataupun sebuah tim, dengan nama "Tim Namlea" karena diawali oleh huruf "N" kapital.

"Opak" merupakan bentuk jargon yang tergolong kelas kata benda. "Opak" digunakan sebagai sandi yang dapat memperjelas untuk ditujukan oleh suatu tempat, benda, ataupun sebuah tim, dengan nama "Tim Opak" karena nama depannya diawali oleh huruf "O” kapital. "Pati" merupakan bentuk jargon yang tergolong kelas kata benda. "Pati" digunakan sebagai sandi yang dapat memperjelas untuk ditujukan oleh suatu tempat, benda, ataupun sebuah tim, dengan nama "Tim Pati" karena diawali oleh huruf "P" kapital.

(17) “Queen" merupakan bentuk jargon yang tergolong kelas kata benda. "Queen" digunakan sebagai sandi yang dapat memperjelas untuk ditujukan oleh suatu tempat, benda, ataupun sebuah tim, dengan nama "Tim Queen" karena nama depannya diawali oleh huruf "Q" kapital.

(18) "Rembang" merupakan bentuk jargon y yang tergolong kelas kata benda. "Rembang" digunakan sebagai sandi yang dapat memperjelas untuk ditujukan oleh suatu tempat, benda, ataupun sebuah tim, dengan nama "Tim Rembang" karena nama depannya diawali oleh huruf "R" kapital. 
(19)

"Solo" merupakan bentuk jargon yang tergolong kelas kata benda. "Solo" digunakan sebagai sandi yang dapat memperjelas untuk ditujukan oleh suatu tempat, benda, ataupun sebuah tim, dengan nama "Tim Solo" karena nama depannya diawali oleh huruf " $S$ " kapital.

"Timor" merupakan bentuk jargon yang tergolong kelas kata benda. "Timur" digunakan sebagai sandi yang dapat memperjelas untuk ditujukan oleh suatu tempat, benda, ataupun sebuah tim, dengan nama "Tim Timor" karena nama depannya diawali oleh huruf "T" kapital.

(21) "Ungaran" merupakan bentuk jargon yang tergolong kelas kata benda. "Ungaran" digunakan sebagai sandi yang dapat memperjelas untuk ditujukan oleh suatu tempat, benda, ataupun sebuah tim, dengan nama "Tim Ungaran" karena nama depannya diawali oleh huruf "U” kapital.

"Viktor" merupakan bentuk jargon yang tergolong dalam sandi Alfabet lokal/Indonesia, jargon tersebut termasuk ke dalam kelas kata benda. "Victor" digunakan sebagai sandi yang dapat memperjelas untuk ditujukan oleh suatu tempat, benda, ataupun sebuah tim, dengan nama "Tim Viktor" karena nama depannya diawali oleh huruf "V" kapital.

"Wilis" merupakan bentuk jargon yang tergolong kelas kata benda. "Wilis" digunakan sebagai sandi yang dapat memperjelas untuk ditujukan oleh suatu tempat, benda, ataupun sebuah tim, dengan nama "Tim Wilis" karena nama depannya diawali oleh huruf "W" kapital.

"X-tra/ Ekstra" merupakan bentuk jargon yang tergolong kelas kata benda. "X-tra" digunakan sebagai sandi yang dapat memperjelas untuk ditujukan oleh suatu tempat, benda, ataupun sebuah tim, dengan nama "Tim X-tra" karena nama depannya diawali oleh huruf "X" kapital.

"Yongki" merupakan bentuk jargon yang tergolong kelas kata benda. "Yongki" digunakan sebagai sandi yang dapat memperjelas untuk ditujukan oleh suatu tempat, benda, ataupun sebuah tim, dengan nama "Tim Yongki" karena nama depannya diawali oleh huruf "Y" kapital. 
(26) "Zainal" merupakan bentuk jargon yang yang tergolong kelas kata benda. "Zainal" digunakan sebagai sandi yang dapat memperjelas untuk ditujukan oleh suatu tempat, benda, ataupun sebuah tim, dengan nama "Tim Zainal" Karena nama depannya diawali oleh huruf “ $Z$ ” kapital.

(27) Kata "Wibawa" merupakan bentuk jargon yang tergolong dalam sandi kata, jargon tersebut termasuk ke dalam kelas kata benda. Secara maknanya kata wibawa memiliki makna pimpinan tertinggi di lingkungan Satuan Polisi Pamong Praja Pada Markas Komando Kabupaten Karawang.

(28) Kata "Tameng" merupakan bentuk jargon yang tergolong dalam sandi kata, jargon tersebut termasuk ke dalam kelas kata benda. Secara maknanya kata Tameng memiliki makna Kapelops di lingkungan Satuan Polisi Pamong Praja Pada Markas Komando Kabupaten Karawang.

(29) Kata "Taruna" merupakan bentuk jargon yang tergolong dalam sandi kata, jargon tersebut termasuk ke dalam kelas kata benda. Secara maknanya kata Taruna memiliki makna Berita/Informasi.

(30) Kata "Gelombang" merupakan bentuk jargon yang tergolong dalam sandi kata, jargon tersebut termasuk ke dalam kelas kata benda. Secara maknanya kata Gelombang memiliki makna Jam/Waktu.

(31) Kata "Semut" merupakan bentuk jargon yang tergolong dalam sandi kata, jargon tersebut termasuk ke dalam kelas kata benda. Secara maknanya kata Semut memiliki makna Pelajar.

(32) Kata "Lalat" merupakan bentuk jargon yang tergolong dalam sandi kata, jargon tersebut termasuk ke dalam kelas kata benda. Secara maknanya kata Lalat memiliki makna Mahasiswa.

(33) Kata "Pangkalan" merupakan bentuk jargon yang tergolong dalam sandi kata, jargon tersebut termasuk ke dalam kelas kata benda. Secara maknanya kata Pangkalan memiliki makna Rumah/Kediaman. 
(34) Kata "Cangkulan" merupakan bentuk jargon yang tergolong dalam sandi kata, jargon tersebut termasuk ke dalam kelas kata benda. Secara maknanya kata Cangkulan memiliki makna Kantor/Tempat Kerja.

(35) Kata "Gajah" merupakan bentuk jargon yang tergolong dalam sandi kata, jargon tersebut termasuk ke dalam kelas kata benda. Secara maknanya kata Gajah memiliki makna Derek.

(36) Kata "Cicak" merupakan bentuk jargon yang tergolong dalam sandi kata, jargon tersebut termasuk ke dalam kelas kata benda. Secara maknanya kata Cicak memiliki makna Pemulung.

(37) Kata "Komando" merupakan bentuk jargon yang tergolong dalam sandi kata, jargon tersebut termasuk ke dalam kelas kata benda. Secara maknanya kata Komando memiliki makna Kantor Polisi.

(38) Kata "Tikar" merupakan bentuk jargon yang tergolong dalam sandi kata, jargon tersebut termasuk ke dalam kelas kata benda. Secara maknanya kata Tikar memiliki makna Surat.

(39) Kata "Laka" merupakan bentuk jargon yang tergolong dalam sandi kata, jargon tersebut termasuk ke dalam kelas kata benda. Secara maknanya kata laka memiliki makna kecelakaan.

(40) Kata "Sepi" merupakan bentuk jargon yang tergolong dalam sandi kata, jargon tersebut termasuk ke dalam kelas kata benda. Secara maknanya kata Sepi memiliki makna Senjata Api.

(41) Kata "Sajam" merupakan bentuk jargon yang tergolong dalam sandi kata, jargon tersebut termasuk ke dalam kelas kata benda. Secara maknanya kata Sajam memiliki makna Senjata Tajam.

(42) Kata "Curat" merupakan bentuk jargon yang tergolong dalam sandi kata, jargon tersebut termasuk ke dalam kelas kata benda. Secara maknanya kata Curat memiliki makna Pencurian dengan pemberatan. 
(43) Kata "Curas" merupakan bentuk jargon yang tergolong dalam sandi kata, jargon tersebut termasuk ke dalam kelas kata benda. Secara maknanya kata Curas memiliki makna Pencurian dengan kekerasan.

(44) Kata "Curanmor" merupakan bentuk jargon yang tergolong dalam sandi kata, jargon tersebut termasuk ke dalam kelas kata benda. Secara maknanya kata Curanmor memiliki makna Pencurian kendaraan bermotor.

(45) Kata "Monik" merupakan bentuk jargon yang tergolong dalam sandi kata, jargon tersebut termasuk ke dalam kelas kata benda. Secara maknanya kata Monik memiliki makna Anak.

(46) Kata "Wayang" merupakan bentuk jargon yang tergolong dalam sandi kata, jargon tersebut termasuk ke dalam kelas kata benda. Secara maknanya kata Wayang memiliki makna Intel/Serse.

(47) Kata "Panah" merupakan bentuk jargon yang tergolong dalam sandi kata, jargon tersebut termasuk ke dalam kelas kata benda. Secara maknanya kata Panah memiliki makna Polantas.

\section{b. Bentuk Lingual 'Frasa' Pada Jargon Satuan Polisi Pamong Praja Pada Markas Komando Kabupaten Karawang}

Bentuk frasa yang tedapat pada Jargon Satuan Polisi Pamong Praja Pada Markas Komando Kabupaten Karawang terdapat pada frasa numerial dan frasa nomina.

\section{(1) Frasa Numeralia Pada Jargon Satuan Polisi Pamong Praja Pada Markas Komando Kabupaten Karawang}

Berikut ini penulis akan memberikan contoh jargon yang termasuk dalam frasa numerial : 
Satu Satu, Satu Empat, Tiga Tiga, Tiga Tiga L, Tiga Tiga M, Tiga Tiga K, Tiga Tiga KA, Tiga Empat K, Empat Empat, Lima Lima, Delapan Empat, Delapan Enam, Delapan Tujuh, Delapan Delapan, Sepuluh Dua, Sepuluh Empat, Sepuluh Delapan, Satu Satu Dua, Dua Delapan lima, Tiga Nol Tiga, Tiga Nol Satu, Tiga Tiga Delapan, Tiga Enam Tiga, Tiga Enam Lima, Delapan Satu Sepuluh, Delapan Satu Satu, Delapan Satu Dua, Delapan Satu Tiga, Delapan Satu Empat, Delapan Satu Lima, Delapan Satu Enam, Delapan Satu Sembilan, Delapan Satu Sepuluh, Juang Satu Alpa, Juang Satu Bravo, Juang Satu Carli, Juang Dua Alpa, Juang Dua Bravo, Juang Tiga Alpa, Juang Tiga Bravo, Juang Empat Alpa, Juang Empat Bravo, Juang Lima Alpa, Juang Lima Bravo, Jaya 65.

(1) Frasa "Satu-Satu" termasuk ke dalam jargon berbentuk frasa numeralia karena terbentuk dari kata bilangan. Frasa ini memiliki makna Hubungi Via Hp/Telepon, Frasa ini biasa digunakan oleh Satpol PP pada saat bertugas meminta sambungan segera menghubungi melalui telephone/Hp.

(2) Frasa "Satu-Empat" termasuk ke dalam jargon berbentuk frasa numeralia karena terbentuk dari kata bilangan. Frasa ini memiliki makna ingin berbicara di udara, Frasa ini biasa digunakan oleh Satpol PP pada saat bertugas meminta berbicara di udara pada lawan penuturnya.

(3) Frasa "Satu-satu-dua" termasuk ke dalam jargon berbentuk frasa numeralia karena terbentuk dari kata bilangan. Frasa ini memiliki makna emergency/darurat, Frasa ini biasa digunakan oleh Satpol PP pada saat bertugas dalam keadaan emergency/darurat pada lawan penuturnya.

(4) Frasa "Dua-delapan-lima-" termasuk ke dalam jargon berbentuk frasa numeralia karena terbentuk dari kata bilangan. Frasa ini memiliki makna pemerkosaan, Frasa ini biasa digunakan oleh Satpol PP pada saat bertugas berkaitan dengan pemerkosaan untuk disambungkan pada lawan penuturnya.

(5) Frasa "Tiga-tiga" termasuk ke dalam jargon berbentuk frasa numeralia karena terbentuk dari kata bilangan. Frasa ini memiliki makna kualitas suara jelek, Frasa ini biasa digunakan oleh Satpol PP pada saat bertugas bahwa kualitas suara saat ini jelek untuk disambungkan pada lawan penuturnya. 
(6) Frasa "Tiga-tiga-lombok-" termasuk ke dalam jargon berbentuk frasa numeralia karena terbentuk dari kata bilangan. Frasa ini memiliki makna kecelakaan korban luka ini biasa digunakan oleh Satpol PP pada saat bertugas berkaitan dengan kejadian kecelakaan korban yang terluka untuk disambungkan pada lawan penuturnya.

(7) Frasa "Tiga-tiga-medan-" termasuk ke dalam jargon berbentuk frasa numeralia karena terbentuk dari kata bilangan. Frasa ini memiliki makna kecelakaan korban material, Frasa ini biasa digunakan oleh Satpol PP pada saat bertugas berkaitan pada kecelakaan korban material untuk disambungkan kepada lawan penuturnya.

(8) Frasa "Tiga-tiga KA-" termasuk ke dalam jargon berbentuk frasa numeralia karena terbentuk dari kata bilangan. Frasa ini memiliki makna kecelakaan kereta api, Frasa ini biasa digunakan oleh Satpol PP pada saat bertugas berkaitan dengan kecelakaan kereta api tuk disambungkan pada lawan penuturnya.

(9) Frasa "Tiga-empat-kendal-" termasuk ke dalam jargon berbentuk frasa numeralia karena terbentuk dari kata bilangan. Frasa ini memiliki makna kecelakaan korban meninggal/pelaku melarikan diri, Frasa ini biasa digunakan oleh Satpol PP pada saat bertugas berkaitan dengan kecelakaan korban meninggal/pelaku melarikan diri untuk disambungkan pada lawan penuturnya.

(10) Frasa "Tiga-kosong-satu-" termasuk ke dalam jargon berbentuk frasa numeralia karena terbentuk dari kata bilangan. Frasa ini memiliki makna lagi kimpoi, Frasa ini biasa digunakan oleh Satpol PP pada saat bertugas berkaitan aktifitas lagi kimpoi untuk disambungkan pada lawan penuturnya.

(11) Frasa "Tiga-kosong-tiga" termasuk ke dalam jargon berbentuk frasa numeralia karena terbentuk dari kata bilangan. Frasa ini memiliki makna perjudian, Frasa ini biasa digunakan oleh Satpol PP pada saat bertugas berkaitan dengan perjudian untuk disambungkan pada lawan penuturnya. 
(12) Frasa "Tiga-tiga-delapan-" termasuk ke dalam jargon berbentuk frasa numeralia karena terbentuk dari kata bilangan. Frasa ini memiliki makna pembunuhan, Frasa ini biasa digunakan oleh Satpol PP pada saat bertugas berkaitan dengan pembunuhan untuk disambungkan pada lawan penuturnya.

(13) Frasa "Tiga-enam-tiga-" termasuk ke dalam jargon berbentuk frasa numeralia karena terbentuk dari kata bilangan. Frasa ini memiliki makna pencurian, Frasa ini biasa digunakan oleh Satpol PP pada saat bertugas berkaitan dengan pencurian untuk disambungkan pada lawan penuturnya.

(14) Frasa "Tiga-enam-lima-" termasuk ke dalam jargon berbentuk frasa numeralia karena terbentuk dari kata bilangan. Frasa ini memiliki makna perampokan, Frasa ini biasa digunakan oleh Satpol PP pada saat bertugas berkaitan dengan perampokan untuk disambungkan pada lawan penuturnya.

(15) Frasa "Empat-empat-" termasuk ke dalam jargon berbentuk frasa numeralia karena terbentuk dari kata bilangan. Frasa ini memiliki makna penerimaan jelek, Frasa ini biasa digunakan oleh Satpol PP pada saat bertugas berkaitan penerimaan jelek atau sama halnya dengan kualitas suara jelek untuk disambungkan pada lawan penuturnya.

(16) Frasa "lima-lima-" termasuk ke dalam jargon berbentuk frasa numeralia karena terbentuk dari kata bilangan. Frasa ini memiliki makna penerimaan baik, Frasa ini biasa digunakan oleh Satpol PP pada saat bertugas berkaitan penerimaan baik lawan dari frasa "empat-empat"untuk disambungkan pada lawan penuturnya.

(17) Frasa "Delapan-empat-" termasuk ke dalam jargon berbentuk frasa numeralia karena terbentuk dari kata bilangan. Frasa ini memiliki makna tes pesawat/tes penerimaan, Frasa ini biasa digunakan oleh Satpol PP pada saat bertugas berkaitan dengan test pesawat/test penerimaan mengecek kulitas sambungan untuk disambungkan pada lawan penuturnya.

(18) Frasa "Delapan-enam-" termasuk ke dalam jargon berbentuk frasa numeralia karena terbentuk dari kata bilangan. Frasa ini memiliki makna di mengerti, 
Frasa ini biasa digunakan oleh Satpol PP pada saat bertugas siap dimengerti atas perintah untuk disambungkan pada lawan penuturnya.

(19) Frasa "Delapan-tujuh-" termasuk ke dalam jargon berbentuk frasa numeralia karena terbentuk dari kata bilangan. Frasa ini memiliki makna di sampaikan, Frasa ini biasa digunakan oleh Satpol PP pada saat bertugas menjawab pentur jargon tersebut agar di sampaikan untuk disambungkan pada lawan penuturnya.

(20) Frasa "Delapan-delapan" termasuk ke dalam jargon berbentuk frasa numeralia karena terbentuk dari kata bilangan. Frasa ini memiliki makna ingin berjumpa langsung, Frasa ini biasa digunakan oleh Satpol PP pada saat bertugas kepada lawan bicaranya ingin berjumpa langsung untuk disambungkan pada lawan penuturnya.

(21) Frasa "Delapan-satu-satu" termasuk ke dalam jargon berbentuk frasa numeralia karena terbentuk dari kata bilangan. Frasa ini memiliki makna kembali mengudara/memancar, Frasa ini biasa digunakan oleh Satpol PP pada saat bertugas berkaitan kembali mengudara/memancar untuk disambungkan pada lawan penuturnya.

(22) Frasa "Delapan-satu-dua" termasuk ke dalam jargon berbentuk frasa numeralia karena terbentuk dari kata bilangan. Frasa ini memiliki makna berita agar di ulang/kurang jelas, Frasa ini biasa digunakan oleh Satpol PP pada saat bertugas berkaitan pengulangan bicara karena kualitas suara tidak jelas untuk disambungkan pada lawan penuturnya.

(23) Frasa "Delapan-satu-tiga" termasuk ke dalam jargon berbentuk frasa numeralia karena terbentuk dari kata bilangan. Frasa ini memiliki makna selamat bertugas, Frasa ini biasa digunakan oleh Satpol PP pada saat bertugas berkaitan ucapan selamat bertugas untuk disambungkan pada lawan penuturnya.

(24) Frasa "Delapan-satu-empat" termasuk ke dalam jargon berbentuk frasa numeralia karena terbentuk dari kata bilangan. Frasa ini memiliki makna 
laporan/pembicaraan terlalu cepat, Frasa ini biasa digunakan oleh Satpol PP pada saat bertugas berkaitan laporannya /pembicaraannya terlalu cepat untuk disambungkan pada lawan penuturnya.

(25) Frasa "Delapan-satu-lima" termasuk ke dalam jargon berbentuk frasa numeralia karena terbentuk dari kata bilangan. Frasa ini memiliki makna cuaca, Frasa ini biasa digunakan oleh Satpol PP pada saat bertugas berkaitan keadaan cuaca untuk disambungkan pada lawan penuturnya.

(26) Frasa "Delapan-satu-enam" termasuk ke dalam jargon berbentuk frasa numeralia karena terbentuk dari kata bilangan. Frasa ini memiliki makna jam/waktu, Frasa ini biasa digunakan oleh Satpol PP pada saat bertugas berkaitan dengan jam/waktu untuk disambungkan pada lawan penuturnya.

(27) Frasa "Delapan-satu-sembilan" termasuk ke dalam jargon berbentuk frasa numeralia karena terbentuk dari kata bilangan. Frasa ini memiliki makna situasi, Frasa ini biasa digunakan oleh Satpol PP pada saat bertugas berkaitan dengan situasi untuk disambungkan pada lawan penuturnya.

(28) Frasa "Delapan-satu-sepuluh" termasuk ke dalam jargon berbentuk frasa numeralia karena terbentuk dari kata bilangan. Frasa ini memiliki makna pembunuhan, Frasa ini biasa digunakan oleh Satpol PP pada saat bertugas berkaitan dengan pembunuhan untuk disambungkan pada lawan penuturnya.

(29) Frasa "Sepuluh-dua" termasuk ke dalam jargon berbentuk frasa numeralia karena terbentuk dari kata bilangan. Frasa ini memiliki makna posisi/keberadaan, Frasa ini biasa digunakan oleh Satpol PP pada saat bertugas berkaitan dengan posisi/keberadaan untuk disambungkan pada lawan penuturnya.

(30) Frasa "Sepuluh-empat" termasuk ke dalam jargon berbentuk frasa numeralia karena terbentuk dari kata bilangan. Frasa ini memiliki makna Di terima, Frasa ini biasa digunakan oleh Satpol PP pada saat bertugas berkaitan dengan penerimaan untuk disambungkan pada lawan penuturnya. 
(31) Frasa "Sepuluh-delapan" termasuk ke dalam jargon berbentuk frasa numeralia karena terbentuk dari kata bilangan. Frasa ini memiliki makna Menuju, Frasa ini biasa digunakan oleh Satpol PP pada saat bertugas sedang menuju untuk disambungkan pada lawan penuturnya.

(32) Frasa "Jaya 65" termasuk ke dalam jargon berbentuk frasa numeralia karena terbentuk dari kata bilangan. Frasa ini memiliki makna kebakaran, Frasa ini biasa digunakan oleh Satpol PP pada saat bertugas sedang menuju untuk disambungkan pada lawan penuturnya.

Data jargon di atas merupakan seluruh dari data penulis jargon yang merupakan frasa numeralia atau di bentuk dari kata bilangan. Berikut contoh Dalam pemakaian frasa numeralia:

Data (001)

"Monitor, delta pati cek 8-1-9 (delapan empat sembilan).

Arti dari percakapan dialog data (001) diatas, bahwa komandan provost diminta untuk mengabarkan situasi setempat.

Data (002)

"Delta alpa, himbau anggota solo garut aksi solo medan ungaran 108(sepuluh delapan) pemda.

Arti dari percakapan dialog data (002) diatas, danru diperintahkan menghimbau anggota untuk bersiaga aksi mahasiswa yang sedang menuju pemda.

Data (003)

"Monitor, pati alpa 3-3-L (tiga tiga lombok) di karangpawitan.

Arti dari percakapan dialog data (003) diatas, anggota provost dimintan untuk ke kawasan karang pawitan karena ada kecelakaan korban luka.

Data (004) 
"Delta carli, wibawa 1-1 (satu satu) olrh praja carli.

Arti dari percakapan dialog data (004) diatas, bahwa Danru III diminta untuk menghadap kepala bidang linmas, kasatpol pp ingin di hubungi melalui Hp.

Data (005)

"Seluruh anggota, 8-1-3 (delapan satu tiga) terimakasih

Arti dari percakapan dialog data (005) diatas, seluruh anggota selamat bertugas, terima kasih.

\section{(2) Frasa Nomina Pada Jargon Satuan Polisi Pamong Praja Pada Markas Komando Kabupaten Karawang}

Berikut ini adalah contoh jargon yang termasuk ke dalam frasa nomina :

Medan-medan, Timor Medan, Rembang Solo, bandung umar solo, Halong Pati.

(1) "Medan-medan" termasuk ke dalam frasa nomina karena terdiri dari gabungan kata benda, yaitu medan. Frasa nomina ini memiliki arti metro mini Frasa ini biasa digunakan oleh Satpol PP pada saat berkomunikasi untuk mempermudah dalam berkomunikasi.

(2) “Timor-Medan" termasuk ke dalam frasa nomina karena dalam jargon tersebut mengandung kata yang terdiri dari gabungan kata benda yaitu medan. Frasa nomina ini memiliki arti metro mini Frasa ini biasa digunakan oleh Satpol PP pada saat berkomunikasi untuk mempermudah dalam berkomunikasi.

(3) "Rembang-solo" termasuk ke dalam frasa nomina karena dalam jargon tersebut mengandung kata yang terdiri dari gabungan kata benda yaitu solo. Frasa nomina ini memiliki arti rumah sakit Frasa ini biasa digunakan oleh 
Satpol PP pada saat berkomunikasi untuk mempermudah dalam berkomunikasi.

(4) “Timor-Medan" termasuk ke dalam frasa nomina karena dalam jargon tersebut mengandung kata yang terdiri dari gabungan kata benda yaitu medan. Frasa nomina ini memiliki arti tamu/teman Frasa ini biasa digunakan oleh Satpol PP pada saat berkomunikasi untuk mempermudah dalam berkomunikasi.

(5) "Bandung-umar-solo" termasuk ke dalam frasa nomina karena dalam jargon tersebut mengandung kata yang terdiri dari gabungan kata benda yaitu solo. Frasa nomina ini memiliki arti bus Frasa ini biasa digunakan oleh Satpol PP pada saat berkomunikasi untuk mempermudah dalam berkomunikasi.

(6) Halong-Pati" termasuk ke dalam frasa nomina karena dalam jargon tersebut mengandung kata yang terdiri dari gabungan kata benda yaitu solo. Frasa nomina ini memiliki arti Handp Phone Frasa ini biasa digunakan oleh Satpol PP pada saat berkomunikasi untuk mempermudah dalam berkomunikasi.

Data (001)

"Monitor, pati alpa, medan medan segera di tertibkan.

Arti dari percakapan dialog data (001) diatas, monitor kepada anggota provost metro mini segera di tertibkan.

Data (002)

"Delta alpa, lapor wibawa timor medan dari bandung.

Arti dari percakapan dialog data (002) diatas, Danru I lapor kepada kasatpol pp ada tamu dari bandung.

Data (003)

"Pati alpa, PKL area rembang solo bayukarta, segera di tertibkan.

Arti dari percakapan dialog data (003) diatas, Anggota provost untuk PKL di area rumah sakit bayukarta segera di tertibkan.

Data (004) 
"Delta carli, bandung umar solo di area pemda segera di tertibkan.

Arti dari percakapan dialog data (004) diatas, danru III diminta BUS yang berada di areal pemda segera di tertibkan.

\section{Makna Jargon ditinjau dari Komponen Tutur Jargon Satuan Polisi Pamong Praja Pada Markas Komando Kabupaten Karawang}

Mengacu pada kajian yang akan penulis terapkan dalam pembahasan ini secara linguistik dengan konsep peristiwa tutur, (Hymes, 1989: 56). Berikut adalah salah satu tindak tutur yang di lakukan oleh Satuan Polisi Pamong Praja pada Markas Komando Kabupaten Karawang :

Data (001)

Praja Alpa : Selamat Pagi, Monitor?

Praja Bravo: Ijin posisi

Praja Alpa : Plaza Pemda.

Praja Bravo : Ijin menghadap.

Praja Alpa : Merapat ke mako gelombang 13.00 Wib

Bravo : Siap 86.

Setting adalah sesuatu yang berkenaan dengan waktu dan tempat tutur berlangsung, sedangkan secene adalah mengacu pada situasi tempat dan waktu atau waktu psikologis pembicaraan. Dari data (001) tempat berlangsungnya komunikasi terjadi pada Markas Komando Kabupaten Karawang. Situasi tempat dan waktu berlangsung pada pagi hari di plaza pemda Kabupaten Karawang.

Participants adalah pihak-pihak yang terlibat dalam pertuturan, bisa pembicara dan pendengar, penyapa, dan pesapa, atau pengirim dan penerima (Pesan). Pihak-pihak yang terlibat adalah Praja Alpa sebagai pentutur awal dalam dialog tersebut dan Praja Bravo pendengar sekaligus menjawab dalam dialog tersebut 
Ends merujuk pada maksud dan tujuan dalam pertuturan. Tujuan pada peristiwa data (001) di atas adalah Praja Bravo ingin bertemu dengan Praja Alpa di mako.

Act sequences adalah mengacu pada bentuk ujaran dan isi ujaran yang berkenaan kata-kata yang digunakan, bagaimana penggunaannya, dan hubungan antara apa yang dikatakan dengan topik pembicaraan. Kata yang digunakan oleh Praja Alpa dan Praja Bravo pada saat mereka berdialog menggunakan bahasa Jargon, berbeda ketika mereka sudah bertemu dan bertatap muka langsung mereka pasti menggunakan bahasa sehari-hari.

Key adalah mengacu pada nada, cara, dan semangat dimana suatu pesan di sampaikan dengan senang hati, dengan serius, dengan singkat, dengan sombong, dan karakter lainnya. Nada yang digunakan oleh Praja Alpa dan Praja Bravo dengan nada informative dan serius, informasi yang digunakan dengan singkat dan jelas menggunakan jargon.

Instrumentalities mengacu pada jalur bahasa yang digunakan seperti jalur lisan, jalur tulis, melalui telegraf atau telepon. Instrumentalities ini juga mengacu pada kode ujaran yang digunakan seperti bahasa, dialek, fragam atau register. Dialog antar Praja Alpa dan Praja Bravo mereka menggunakan jalaur bahasa lisan secara langsung dengan menggunakan Handy Talky (HT) atau mereka dapat menggunakan Handphone untuk lebih jelas dalam berkomunikasi.

Norm of interaction And Interpretation mengacu pada norma atau aturan dalam berinteraksi. Misalnya yang berhubungan dengan cara berin terupsi ,bertanya, dan sebagainya. Data (001) menunjukan bahwa Praja Alpa meminta sambungan kepada seluruh jajaran, namun Praja Bravo menjawab tuturan Praja Alpa untuk meminta waktu untuk bertemu dan menghadap ke Praja Alpa.

Genres mengacu pada jenis bentuk penyampaian, seperti narasi, puisi,pepatah, doa dan sebagainya. Dari tuturan data (001) di atas, Praja Alpa dan Praja Bravo sudah dipastikan menyampaikan informasi melalui secara lisan dengan menggunakan HT. 


\section{Data (002)}

Pati Demak : Pati Bravo, selamat sore,?

Pati Demak: Pati Bravo masuk taruna, ganti...

Praja Bravo: Tolong 8-7 ke anggota agar kumpul untuk giat patrol di kawasan pasar johar pukul $16.00 \mathrm{Wib}$

Pati Demak : 86, Pati Bravo.

Setting adalah sesuatu yang berkenaan dengan waktu dan tempat tutur berlangsung, sedangkan scene adalah mengacu pada situasi tempat dan waktu atau waktu psikologis pembicaraan. Dari data (002) diatas, tempat berlangsungnya komunikasi terjadi di lingkungan Markas Komando Kabupaten Karawang. Situasi tempat dan waktu berlangsung pada sore hari di markas komando Kabupaten Karawang.

Participants adalah pihak-pihak yang terlibat dalam pertuturan, bisa pembicara dan pendengar, penyapa, dan pesapa, atau pengirim dan penerima (Pesan). Pihak-pihak yang terlibat adalah Pati Demak sebagai pentutur awal dalam dialog tersebut dan Pati Bravo pendengar sekaligus menjawab dalam dialog tersebut.

Ends merujuk pada maksud dan tujuan dalam pertuturan. Tujuan pada peristiwa data (001) di atas adalah Pati Demak sedang menunggu informasi dari Pati Bravo untuk kegiatan sore hari.

Act sequences adalah mengacu pada bentuk ujaran dan isi ujaran yang berkenaan kata-kata yang digunakan, bagaimana penggunaannya, dan hubungan antara apa yang dikatakan dengan topik pembicaraan. Kata yang digunakan oleh Pati Demak dan Pati Bravo pada saat mereka berdialog menggunakan bahasa Jargon, berbeda ketika mereka sedang bertatap muka langsung mereka pasti menggunakan bahasa sehari-harinya.

Key adalah mengacu pada nada, cara, dan semangat dimana suatu pesan di sampaikan dengan senang hati, dengan serius, dengan singkat, dengan sombong, dan karakter lainnya. Nada yang digunakan oleh Pati Demak dan Pati Bravo 
dengan nada informatif dan serius, informasi yang digunakan dengan singkat dan jelas menggunakan jargon.

Instrumentalities mengacu pada jalur bahasa yang digunakan seperti jalur lisan, jalur tulis, melalui telegraf atau telepon. Instrumentalities ini juga mengacu pada kode ujaran yang digunakan seperti bahasa, dialek, fragam atau register. Dialog antar Pati Demak dan Pati Bravo mereka menggunakan jalur bahasa lisan secara langsung dengan menggunakan Handy Talky (HT) atau mereka dapat menggunakan Handphone untuk menindak lanjuti atas informasi yang di sampaikan oleh Pati Bravo.

Norm of interaction And Interpretation mengacu pada norma atau aturan dalam berinteraksi. Misalnya yang berhubungan dengan cara berin terupsi ,bertanya, dan sebagainya. Data (002) menunjukan bahwa Pati Demak meminta sambungan kepada Pati Bravo menunggu kabar atau berita tentang giat sore hari , namun Pati Bravo menjawab tuturan Pati Demak untuk meminta anggota mempersiapkan

Genres mengacu pada jenis bentuk penyampaian, seperti narasi, puisi,pepatah, doa dan sebagainya. Dari tuturan data (002) di atas, Pati Demak dan Pati Bravo sudah dipastikan menyampaikan informasi melalui secara lisan dengan menggunakan HT.

\section{Simpulan}

Satuan Polisi Pamong Praja sebagai penegak Perda (Peraturan Daerah) yang bertugas mengawal dan tim pelaksana segala bentuk kegiatan yang telah di rumuskan pada rancangan Peraturan Daerah, umumnya pada daerah/kabupaten umumnya di lingkungan Markas Komando Kabupaten Karawang.

Dalam kesimpulan ini penulis akan menyimpulkan hasil pembahasan yang telah penulis uraikan dalam Bab IV, yang pertama ialah mengenai bentuk sandi pada jargon yang digunakan oleh Satuan Polisi Pamong Praja Pada Markas Komando 
Kabupaten Karawang yaitu sandi struktural sandi Alfabet/lokal Indonesia, sandi angka, dan sandi kata.

Kedua, Bentuk lingual pada jargon Satuan Polisi Pamong Praja Pada Markas Komando Kabupaten Karawang terdiri dari bentuk kata dan frasa numeralia dan frasa nomina.

Ketiga, makna jargon di tinjau dari komponen tutur penulis mengacu pada teori SPEAKING yaitu Setting and Scene, Participants, End :Purpose and Goal, Act Squences, Key : Tone or Spirit of Act, Instrumentalities, Norms Of Interaction And Interpretation, dan Genres.

\section{Daftar Pustaka}

Alwasilah, Chaedar. 2011. Linguistik suatu pengantar. Bandung: Angkasa

Aslinda dan Leni Syafyahya. 2007. Pengantar Sosiolinguistik. Bandung : Refika Adiatama

Chaer, Abdul.2007.Linguistik Umum.Jakarta : Rineka Cipta.

Chaer, Abdul dan Leonie Agustina.2010. Sosiolinguistik Perkenalan Awal. Jakarta : Rineka Cipta

Ginanjar, Rian Wahyu dan Pujiati, Tri. Jargon Petugas Keamanan Golden Vienna 1 Rawa Buntu Kecamatan Serpong. Jurnal Sasindo, Vol.6 No 2. Desember 2018. Keraf, Gorys.1981. Diksi dan Gaya Bahasa. Jakarta : PT Gramedia. Nababan.1984.Sosiolinguistik suatu pengantar. Jakarta : PT. Gramedia. Petada, Mansoer. 2015. Sosiolinguistik. Bandung : Angkasa. Rahardi, R. Kunjana. 2010. Kajian Sosiolinguistik. Bogor : Ghalia Indonesia 